\title{
FIDELIZAÇÃO E CO-CRIAÇÃO DE VALOR: UMA VISÃO INTEGRADA
}

\section{Irene Raguenet Troccoli, D. Sc.}

\section{INTRODUÇÃO}

No meio acadêmico da Estratégia Empresarial e do Marketing, vem-se observando aumento do interesse pelos estudos voltados para a fidelização dos consumidor es. Isto se justifica pelo acirramento da concorrência com o qual os produtores de bens e de serviços crescentemente se deparam, e a necessária agilização em suas decisões voltadas para evitar a perda de clientes.

Contudo, esta necessidade vem ocorrendo em um mundo cada vez mais rico em especificidades e em nuances, que impõem, ao decisor empresarial, uma velocidade de apreensão e de entendimento destes elementos que nem sempre se revela possível.

Hoje, não mais é suficiente apenas saber o que o consumidor deseja para garantir-lhe a fidelização. Não mais basta propor um produto ou um serviço que atenda às necessidades percebidas dos clientes, preferencialmente adequado ao poder de compra deste, e com preço afinado com o custo de produção.

Mais do que isto, é necessário que os ofertantes de bens e de serviços entendam o universo que os cerca em aspectos que transcendem seu próprio mundo corporativo. Afinal, seus clientes estão, cada vez mais, envolvidos em uma rede de elementos sociais, psicológicos, ambientais, políticos e tecnológicos que, simultaneamente, interagem para definir sua decisão de consumo. Em outras palavras, o processo decisório de compra - e, a reboque, a fidelização dos clientes - vem-se tornando evento cada vez mais complexo e mutável.

Assim, às tradicionais necessidades econômicas impostas e aos atrativos funcionais exigidos pelos clientes, outros elementos passaram a ser igualmente importantes na busca pela fidelização. Isto porque o ato de consumir frequentemente tem deixado de ser algo simples, especialmente conforme as melhorias sócio-econômico-educacionais da sociedade como um todo a capacitam a tornar-se crescentemente crítica em relação ao que lhe é oferecido.

Academicamente, isto implica a necessidade de uma constante revisita às estratégias de convencimento dos clientes, de forma que sua compreensão à luz destes novos elementos possa, pelo menos, diminuir as chances da deserção da clientela para os concorrentes.

Neste contexto, este artigo visa a entender a proposta lançada por Prahalad \& Ramaswamy (2004), de co-criação do valor dos produtos e serviços a partir de uma parceria entre ofertantes e seus clientes, enquanto elemento relevante na construção da fidelização destes últimos.

Para atingir este propósito, dividiu-se o artigo em cinco partes: 1) definição de fidelização e a justificativa para seu estudo; 2) apresentação dos guidelines da pesquisa acadêmica de Marketing voltada para a retenção dos clientes, realizada ao longo do século XX; 3) apresentação da abordagem à criação de valor proposta por Prahalad \& Ramaswamy (2004); 4) interação desta abordagem ao modelo de fidelização proposto por Oliver (1999); 5) conclusão da análise, e sugestão de novos desenvolvimentos. 


\section{DEFINIÇÃO DA FIDELIZAÇÃO E JUSTIFICATIVA PARA SEU ESTUDO}

A fidelização dos clientes vem sendo estudada - e sua definição proposta - por vários estudiosos acadêmicos, que invariavelmente a atrelam ao estudo da satisfação trazida pelo consumo de um bem ou serviço. De fato, em princípio esta ligação faz sentido, partindo-se do raciocínio de que um consumidor deverá - ou não - tornar-se fiel a um produto ou serviço conforme este último lhe traga - ou não - algum nível de satisfação.

Porém, vale observar que, como veremos no próximo item, esta relação é assimétrica, pois, embora a lealdade implique satisfação, esta última nem sempre implica lealdade.

No que tange à definição de fidelização, Oliver (1999) chamou a atenção para o fato de que os acadêmicos tradicionalmente lançaram propostas que remetiam, primordialmente, ao processo que gera a fidelização. Em outras palavras, eles

“... definem o que os consumidores fazem para tornarem-se satisfeitos e/ou leais...registrando o que o consumidor faz. Ninguém toca no significado psicológico da satisfação ou da lealdade." (p. 34).

Movido por esta sensação de insuficiência, já anteriormente Oliver (1997) propusera que a satisfação fosse definida como uma realização prazerosa, indicando que o consumo do bem ou serviço preencheu alguma necessidade, desejo e/ou objetivo, e que este preenchimento foi prazeroso. Além disto, ele também propôs que a fidelização do cliente surgiria conforme este preenchimento prazeroso se tornasse frequente, cumulativo, até que os episódios de satisfação se agregassem e se fundissem.

Prosseguindo em seu trabalho de pesquisa, Oliver (1999) foi além do seu ponto-de-vista construído dois anos antes, tendo avaliado que aquela frequência e acumulação não seriam, por si sós, suficientes para gerar a satisfação do cliente. Para tanto, este último teria que ter-se movido para um plano conceitual que transcendesse a mera satisfação, e que incluísse o ato do consumo em si.

Foi a partir deste achado que o autor propôs, como definição da fidelidade dos clientes - que adotaremos neste trabalho - o seguinte:

Um comprometimento profundo em consistentemente recomprar ou preferir um produto ou serviço no futuro ... apesar de influências situacionais e de esforços de marketing que busquem levar o consumidor a trocar de fornecedor. (p. 34).

À luz desta definição, não é difícil entender-se o porquê de o estudo da fidelização dos clientes vir ocupando uma parcela tão relevante da literatura do Marketing, além de ter servido, em grande monta, para subsidiar a pesquisa acadêmica das estratégias empresariais. Afinal, o maior desejo de qualquer empresário é que seu cliente lhe seja fiel, retornando à aquisição do produto e serviço: conforme Machado (2004),são evidentes os resultados positivos financeiros quando se tem uma base de clientes fiéis. (p. 1).

Da mesma forma, não é difícil entender-se o porquê de algumas empresas terem levado o conceito da fidelização a um limite alheio ao seu propósito original - o de um ganha-ganha entre empresário e cliente - a ponto de imporem um verdadeiro aprisionamento do cliente travestido de fidelização, e, o que é pior, não verem nenhum malefício nesta prática. Qualquer semelhança com a política praticada pelas empresas de telefonia móvel brasileiras, de subsidiarem a venda de seus aparelhos a troco da permanência compulsória do cliente como 
usuário dos serviços durante o tempo determinado pela empresa, não é mera coincidência.

\section{GUIDELINES DA PESQUISA ACADÊMICA DE MARKETING VOLTADA PARA A RETENÇÃo DOS CLIENTES NO SÉCULO XX}

Dada a importância da lealdade a marcas, não surpreende que ela tenha recebido atenção considerável da literatura de marketing desde o artigo seminal de Copeland (1923), um dos precursores do pensamento de marketing e pertencente à primeira escola desta doutrina - a Escola Commodity, criada por volta de 1900 com foco nas transações e vendas de objetos.

Sua gênese inclui estudos a respeito do comportamento dos consumidores desenvolvidos na primeira metade do século passado - Armstrong (1950), Brown (1952) - os quais, por sua vez, encontram raízes na Teoria da Preferência Revelada (Samuelson, 1938).

A fidelização em si, cujas primeiras avaliações foram particularizadas para marcas de produtos físicos, passou a tomar corpo na década de 1970, conforme, por exemplo, Jacoby (1971, 1975, 1978), Jacoby \& Kyner (1973) e Jacoby \& Olson $(1970,1971)$ iniciaram o desenvolvimento de suas pesquisas.

A esta época, a pesquisa de Marketing voltada para a retenção de clientes era apoiada na abordagem comportamental, que entendia que um padrão de compras repetido seria suficiente para explicar a fidelidade do cliente. Bass (1974), por exemplo, suportou este ponto de - vista, indo além ao apresentar e testar uma teoria geral de preferência estocástica que caracterizaria os ciclos de repetição de compra, mas cujas partes randômicas lhe impediriam a análise.

Ao final década de 1970, com Jacoby \& Chestnut (1978) a abordagem foi alterada, a partir da criação de uma definição vista, até hoje, como altamente sofisticada já que cobre os aspectos mais importantes da lealdade a marcas, e que tem sido muito utilizada na literatura de Marketing, mesmo que com algumas adaptações - como em Assael (1992), Mowen (1993) e Wilkie (1990).

Para Jacoby \& Chestnut (1978), o ato de repetição da compra nem sempre representaria fidelidade a uma marca, assim como o padrão de compra repetida de uma outra marca também não implicaria não -fidelidade. Fidelidade foi por eles definida como

A resposta comportamental de preferência, expressada, ao longo do tempo, por um decisor em relação a uma ou mais marcas alternativas de um grupo de marcas semelhantes, e é função de processos psicológicos de tomada de decisão e de avaliação. (p. 80).

Esta definição identificou cinco pré-requisitos para a lealdade a uma marca:

1. Resposta comportamental de preferência: se a lealdade a uma marca é uma resposta que exprime uma preferência, isto implica que há uma tendência sistemática à compra de uma marca - ou grupo de marcas - independentemente de decisões de compra passadas (conforme Massy et al., 1970).

2. Expressada ao longo do tempo: uma preferência ocasional para com uma marca em especial não lhe garantiria lealdade. Como o processo é dinâmico, é necessária alguma consistência durante um certo período de tempo. Isto indica que não se deve considerar apenas o número de vezes em que uma marca específica é comprada durante o período 
considerado, mas também o padrão de compra em sucessivas ocasiões.

3. Por um decisor: pode tratar-se de um cliente pessoa física individual, de uma família ou de uma pessoa jurídica. Ou seja, o decisor não precisa ser o comprador em si (por exemplo, o pai efetua uma compra cuja decisão surgiu de um consenso na família). A importância deste elemento se apresenta conforme os membros do grupo decisório possuem diferentes necessidades e/ou usem o bem ou serviço adquirido com propósitos diferentes. Assim, podem ocorrer mudanças no comportamento de escolha do grupo decisório, motivadas por alterações nos propósitos de uso ou nas necessidades, sem que, obrigatoriamente, tenha havido alteração na preferência pela marca.

4. Em relação a uma ou mais marcas alternativas de um grupo de marcas semelhantes: isto implica que

4.1. os consumidores podem, na verdade, ser leais a mais do que uma marca, conforme observaram vários autores (Ehrenberg, 1972; Jacoby, 1971; 0'Leary, 1993). Especialmente no que diz respeito a bens de baixo envolvimento, os clientes freqüentemente não os avaliam em uma escala contínua, apenas classificando-os em uma escala discreta como aceitáveis ou não aceitáveis. Então, se mais de uma marca é aceitável, o cliente pode lhes ser indiferente, manifestando preferência por um grupo de marcas e não por uma marca em especial. Ocorre que este tipo de comportamento de fidelidade multimarca é difícil de ser distinguido da opção por troca de marca, especialmente se existem apenas poucas marcas à disposição. Supondo que haja a opção de escolha de mais do que apenas as marcas A e B, alguém que adquira apenas estas últimas na seqüência $A B B A B A A B$ pode ser definido como um cliente de preferência multimarca. Mas se seu comportamento for o mesmo existindo apenas as marcas A e B à escolha, isto pode ser interpretado como troca de marcas, já que todas as marcas disponíveis são usadas regularmente.

4.2. para haver fidelidade a uma marca, deve haver a opção de escolha entre as alternativas. De acordo com Jacoby \& Chestnut (1978) "Antes de falar-se de lealdade a uma marca, deve-se ter a oportunidade de ser desleal a ela." (p. 82). Ou seja, lealdade a uma marca não pode existir em situação de monopólio, implicando ser da maior importância a determinação da categoria do produto neste tipo de análise.

5. Função de um processo psicológico: as marcas são escolhidas de acordo com critérios internos que resultam em um compromisso para com elas, o que, de acordo com Jacoby \& Chestnut, é um elemento essencial da fidelidade à marca. Este ponto-de-vista está alinhado com o paradigma do processamento da informação, aspecto dominante no estudo do comportamento do consumidor (Bettman, 1979). Embora nem sempre os clientes busquem informações deliberadamente, eles não deixam de tê-la (por exemplo, via publicidade e propaganda), o que pode ser usado para formar algumas crenças sobre as marcas, e levá-los a preferir umas a outras, até tornarem-se fiéis a uma marca em especial. Ou seja, a lealdade a uma marca implica sua compra repetida a partir da aferição positiva do cliente para com ela.

Nesta linha de raciocínio, Jacoby \& Chestnut propuseram um framework inovador para o conceito de fidelidade. Utilizando a abordagem de aspectos psicológicos, afirmaram que a única forma de se obter a fidelidade verdadeira a uma única marca seria por meio do exame simultâneo de três aspectos que orientam o consumidor a escolhê-la: sua crença na marca (o aspecto cognitivo), sua atitude em relação à marca (o aspecto afetivo) e sua intenção em 
relação à marca (o aspecto conativo).

Nesta linha de raciocínio, para estes autores três condições deveriam existir para garantir a existência da fidelidade verdadeira a uma determinada marca (conforme Machado, 2004):

(a) as informações que o consumidor detém sobre uma marca específica devem colocá-la em posição superior à dos concorrentes;

(b) as informações sobre a marca devem estar alinhadas com o posicionamento e a atitude individual do consumidor;

(c) o consumidor deve possuir uma alta intenção de comprar determinada marca e opor-se a marcas alternativas em situações de tomada de decisão. (p.3)

Este framework foi representado em forma de tabela, na qual os vários tipos de fidelidade podem ser visualizados de uma forma prática:

\section{Framework de Jacoby e Chestnut (1978)}

\begin{tabular}{|l|c|c|c|c|}
\hline \multirow{2}{*}{$\begin{array}{c}\text { Compra repetida de } \\
\text { uma: }\end{array}$} & Marca Específica & Múltiplas Marcas & Outra Marca & Nada \\
\cline { 2 - 5 } Marca específica & Fidelidade verdadeira & $\begin{array}{c}\text { Fidelidade a } \\
\text { múltiplas marcas }\end{array}$ & $\begin{array}{c}\text { Recompra sem } \\
\text { fidelidade }\end{array}$ & Comprador eventual \\
\hline Outra marca & $\begin{array}{c}\text { Comprador eventual } \\
\text { de uma outra marca }\end{array}$ & $\begin{array}{c}\text { Fidelidade a } \\
\text { múltiplas marcas }\end{array}$ & $\begin{array}{c}\text { Fidelidade a outra } \\
\text { marca }\end{array}$ & Comprador eventual \\
\hline
\end{tabular}

Fonte: Jacoby e Chestnut (1978)

Esta sofisticação no entendimento do comportamento do consumidor trazida por Jacoby \& Chestnut - o de que a obtenção da satisfação não seria suficiente para garantir a preferência alertou para que a manutenção das vendas (e, portanto, dos retornos financeiros futuros) estaria ameaçada pelo crescimento da competitividade nos mercados de bens e de serviços.

Com isto, a década de 1990 assistiu à enfatização dos aspectos cognitivos, afetivos e conativos no estudo da lealdade dos clientes, contidos na abordagem psicológica de Jacoby \& Chestnut, ao mesmo tempo em que Dick \& Basu (1994) inovaram, trazendo a discussão sobre a atitude relativa.

Esta atitude relativa seria o grau em que a avaliação do consumidor de uma marca é dominante sobre outra. Esta avaliação, por sua vez, seria influenciada por antecedentes cognitivos, afetivos e conativos, sendo que cada um dos três seria formado por diversos elementos:

- Cognitivos: acessibilidade, confiança, centralidade, claridade

- Afetivos: emoções, estado emocional, afeto primário, satisfação

- Conativos: custos de mudança, custos afundados, expectativas

Além destes elementos, Dick \& Basu entendem que fatores sociais e situacionais também influenciam na repetição de compra e na fidelidade dos clientes. No caso, podem afetar a atitude relativa em dois casos: 
- quando a opção por uma marca possa estar indo contra algum princípio - a exemplo do que ocorre no caso da escolha por produtos não ecologicamente corretos.

- quando houver a criação de inconsistências entre a atitude relativa e o comportamento - por exemplo, quando o desabastecimento de sua marca favorita leva o consumidor a adquirir outra.

A importância do estudo da fidelização manteve-se nos anos seguintes, conforme diversos autores enfocaram este aspecto em suas pesquisas voltadas tanto para a garantia do fluxo futuro de clientes, como da consequente manutenção das vendas e dos desejados retornos financeiros futuros.

Jones \& Sasser (1995) são exemplo desta corrente acadêmica, tendo indicado que níveis mais altos de satisfação do cliente não necessariamente se relacionam à repetição da compra. Tanto em mercados mais competitivos quanto em mercados menos competitivos, eles revelaram que consumidores que estejam apenas meramente satisfeitos apresentam alta probabilidade de trocarem de opção, enquanto somente aqueles completamente satisfeitos têm chance de comprar novamente. Intuitivamente isto faz sentido: conforme qualquer pessoa pode se imaginar não voltando a comprar um produto ou serviço com o qual tenha ficado apenas meramente satisfeito.

Vale abrir um parênteses neste ponto para mencionar que o framework construído por Jones \& Sasser para estudar a fidelização dos clientes trouxe, como contribuição extra, a proposta de que nem sempre é interessante, ao produtor de bens ou serviços, buscar a fidelização de alguns clientes, especificamente aqueles cujo comportamento pode ser desinteressante aos empresários. Nesta linha de raciocínio, eles identificaram seis tipos de clientes:

- O Leal: é o cliente feliz, que teve boas experiências com o produto ou serviço, e está pronto a retornar regularmente. Ele possui uma necessidade que é plenamente satisfeita pelo empresário, tornando-se fácil de ser satisfeito.

- O Apóstolo: é o cliente que fica tão satisfeito com a experiência de consumo que não se furta a fazer um boca-a-boca muito positivo a respeito.

- O Traidor: é o cliente que pode estar muito ou meramente insatisfeito com o produto ou serviço, ou nem satisfeito nem insatisfeito, ou até satisfeito, e que possui alta sensibilidade a falhas. Quando estas ocorrem, ele desiste do produto ou serviço, mesmo estando meramente insatisfeito ou até satisfeito. No caso, os empresários deveriam envidar esforços em retê-lo, já que possuem as ferramentas necessárias para torná-lo um cliente altamente satisfeito.

- O Terrorista: é o pior tipo de cliente para uma empresa, já que se trata de alguém que teve uma experiência ruim, e não havia ninguém da empresa para atendê-lo em sua frustração e tentar corrigir o erro. Por isto, ele está com raiva bastante para usar qualquer oportunidade para fazer um boca-a-boca negativo a respeito do produto ou do serviço.

- O Mercenário: é o cliente que não apresenta regras claras e pode reagir de maneiras imprevisíveis. Mesmo estando altamente satisfeito, não demonstra lealdade. É um cliente caro para se conquistar e some com muita facilidade: procura preços baixos, compra por impulso, é dominado por tendências da moda, ou apenas muda pelo prazer 
de mudar.

- O Refém: é aquele que experimentou um péssimo produto ou serviço mas tem que aceitá-lo mesmo assim. Ocorre classicamente no mercado monopolista.

À medida em que estes esforços acadêmicos, registrados ao longo de várias décadas, construíram o entendimento sobre o comportamento do cliente pela ótica da fidelização, formou-se o terreno para que, já no limiar do século XXI, Oliver $(1997,1999)$ viesse a contribuir de forma muito relevante para sua sofisticação.

Em seu primeiro trabalho, Oliver (1997) propôs que a fidelidade existe em um plano conceitual que transcende a satisfação e ocorre de forma crescente, num movimento de hierarquia de aprendizado que vai formando as atitudes dos clientes. Pictoricamente, este conceito poderia ser entendido como uma escada que representa o caminho do crescimento do envolvimento do cliente para com o produto ou serviço.

No caso, conforme a Figura 1, iniciando-se o desenvolvimento da fidelidade em seu estágio mais básico, o cliente avalia o objeto do seu consumo cognitivamente. Ou seja, a partir das informações prévias de que dispõe e que o habilitam a traçar um quadro do custo-benefício daquele consumo, o cliente entende que o produto ou serviço em questão é preferível às demais alternativas.

Esta lealdade cognitiva - baseada apenas na crença sobre a marca - pode não evoluir para os estágios seguintes, caso se trate de um evento rotineiro e não faculte a geração de um estado de satisfação interior (como no caso do serviço de coleta de lixo). Porém, caso haja o processamento da satisfação, isto se torna parte da experiência do cliente, fazendo surgir aspectos afetivos.

Figura 1

\section{Fases do envolvimento do cliente com o produto ou serviço de acordo com o primeiro modelo de fidelização de Oliver (1997)}

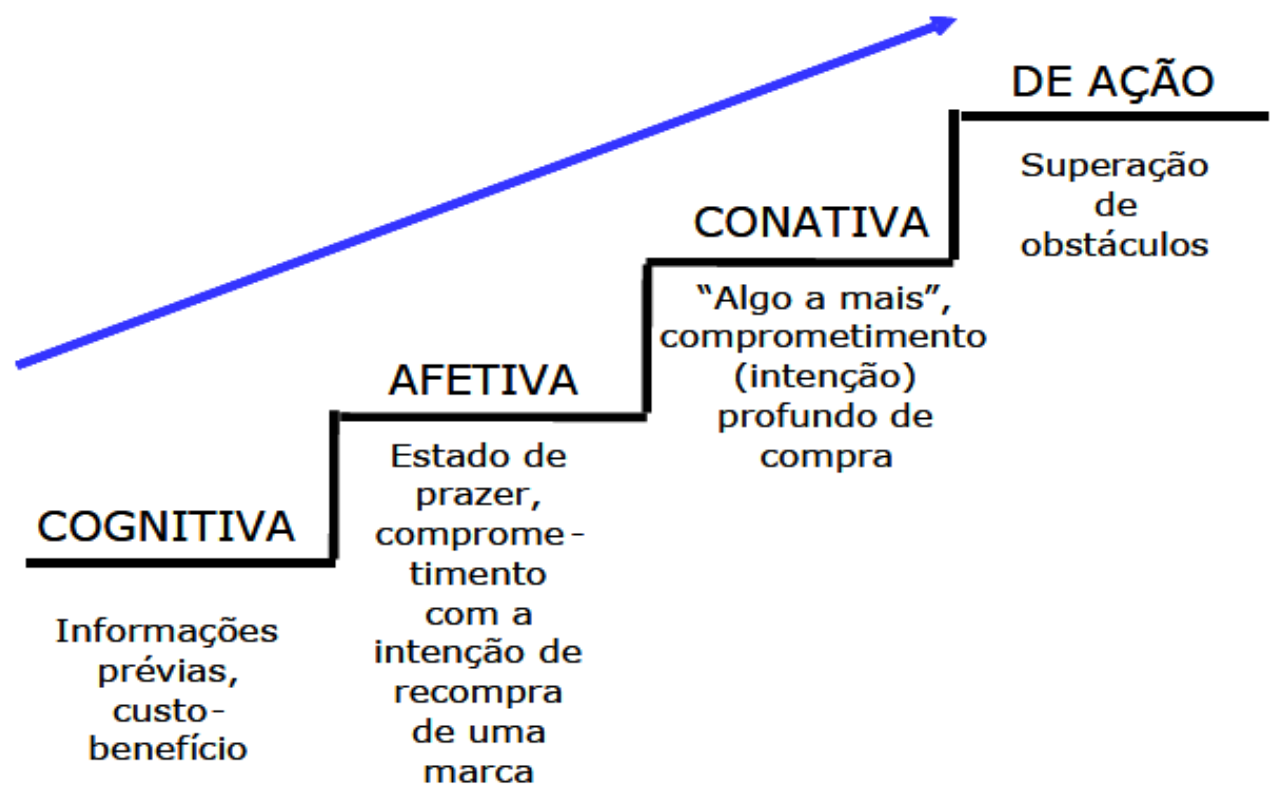

Assim, em seu segundo estágio, o modelo de fidelização proposto por Oliver passa à fase de 
lealdade afetiva: a acumulação de satisfação trazida pela repetição do consumo do bem ou do serviço gera "gosto" pela marca. Como coloca Machado (2004), "O comprometimento com a marca está associado a aspectos afetivos e na mente do consumidor permanecem retidos a cognição e a afetividade." (p. 5). Ademais, enquanto a cognição está diretamente sujeita a contra-argumentações, o afeto não pode ser facilmente derrubado. Mesmo assim, à semelhança do que ocorre na fase cognitiva, aqui a fidelidade não é garantida: não fosse assim, não haveria um percentual tão grande de clientes que, embora se digam satisfeitos com o produto ou serviço, trocam-no por outro.

No seu terceiro estágio, a fidelidade atinge o patamar conativo, ou seja, um comprometimento específico com a recompra daquela marca em especial. No entanto, vale frisar que se trata de comprometimento que, apesar de apresentar-se como uma "boa intenção", pode não se realizar.

Em seu quarto e último estágio, temos finalmente a fidelidade traduzida em ação: o cliente não só está intencionado a recomprar o bem ou serviço, como também estaria disposto a superar eventuais obstáculos para fazê-lo. Neste ponto, portanto, teríamos a consolidação da fidelização, configurando-se o estado de recompra inercial.

Contudo, raciocinando em cima desta modelagem, dois anos após Oliver (1999) observou que não se poderia garantir que o cliente chegaria a desejar recomprar o produto ou serviço a ponto de se propor a superar obstáculos para fazê-lo, tornando-se completamente fiel. Isto ocorreria por vários motivos, um dos quais seriam as ações que estimulam o cliente à troca, tais como a publicidade e a propaganda de marcas concorrentes.

Outro motivo seria a natural idiossincrasia dos clientes, determinada por características que são naturalmente contrárias à fidelidade. Aqui se encaixa, por exemplo, a busca pela variedade, que pode abortar a escalada do processo de fidelização antes que ele alcance seu quarto patamar. Um caso clássico ocorre nos restaurantes: clientes são considerados fiéis mesmo que não deixem de também freqüentar outros lugares.

Outra razão apontada por Oliver para a deslealdade se manifestar remete às alterações nas opções de consumo - por exemplo, o abandono do tabagismo - e às mudanças nas necessidades do cliente.

No segundo caso, Oliver diz que as mudanças podem ocorrer por dois motivos: por amadurecimento do cliente (novas necessidades suplantando antigas, como observado conforme uma criança cresce) ou por meio de uma inovação que passe a satisfazer mais plenamente suas necessidades (por exemplo, no caso da troca de um carro pequeno por um maior conforme a família do condutor aumenta). Vale lembrar que estes motivos também servem para reforçar as mencionadas ações que estimulam à troca.

Com esta linha de raciocínio, Oliver conclui pela fraqueza da seqüência de fidelização que se inicia no estágio cognitivo e termina no estágio da ação. Em qualquer dos quatro estágios o cliente sempre poderá ser tentado a experimentar a troca, conforme os concorrentes da sua marca favorita, ou do seu serviço favorito, saibam explorar as vulnerabilidades de cada fase, tais como:

- Na fase cognitiva: comunicação - via publicidade, por exemplo - de superioridade real ou suposta dos recursos dos competidores; elevada sensibilidade às variações de preço. 
- Na fase afetiva: busca da variedade, experimentação voluntária

- Na fase conativa: oferecimento de amostras grátis (já que, nesta fase, o cliente está comprometido com a marca favorita mas não com a não experimentação de outras).

- Na fase de ação: aquisição de toda a disponibilidade do produto do competidor para forçar o desabastecimento

Partindo dos resultados das pesquisas acadêmicas que mostram que uma unidade de percepção negativa do cliente pesa-lhe muito mais do que uma unidade de percepção positiva (Anderson \& Sullivan, 1993; DeSarbo et al., 1994), Oliver raciocinou que a concorrência sempre tentará ganhar terreno às custas da insatisfação do cliente para com sua marca favorita. A partir daí, ele aperfeiçoou seu modelo de fidelização (Oliver, 1999).

Este aperfeiçoamento se baseou no princípio de que o grande motor da fidelização seria o desenvolvimento do sentimento prazeroso do cliente, a partir do momento em que este, ao preferir uma marca a outras, passa a pertencer a uma "comunidade" da fidelidade.

Este construto - "comunidade" da fidelidade - é definido por Oliver como uma aliança social na qual a motivação primária para a lealdade à marca são a participação no grupo (por parte do cliente) e a satisfação dos desejos dos participantes (por parte dos organizadores). Em outras palavras, “...o cliente submerge sua auto-identidade no sistema social do qual aquela marca faz parte.” (p. 38). Com isto, “...o cliente fervorosamente deseja associar-se ao produto ou serviço, afiliar-se àquele ambiente social, sabendo que este apoiará esta afiliação, e, no limite, ser recompensado pela sua adesão e participação." (p. 38)

Como bons exemplos deste tipo de associação, Oliver cita as instituições religiosas, os fan clubes e as organizações de ex-alunos. Ou seja, o embasamento teórico desta linha de raciocínio reside no sentimento dos indivíduos quando estes entendem que pertencem à comunidade conforme ocorrem a interseção de valores e de comportamentos de consumo (Schouten \& McAlexander, 1995).

No caso, o benefício do cliente ao tornar-se participante da comunidade seria a atenção garantida a seus membros. Em casos-limite, o produto ou serviço não é o que o cliente consome, mas sim a "camaradagem" garantida pela aliança social. Em outras palavras, mais do que a atividade ou o consumo do produto ou do serviço, o que interessa ao cliente é o sentimento de "pertencer". Não por acaso, Oliver menciona que este modo de pensar guarda muitas semelhanças com o conceito de amor, combinando a adoração (um tipo de atenção concentrada) e o comprometimento pleno.

Com isto, ele propõe, como ponto central de seu novo modelo, a existência e o efeito da "comunidade" da fidelidade, aliança social que garante três características no comportamento do cliente:

- Ele opta por se auto-isolar das investidas dos competidores, gerando uma "força individual" que seria como uma repulsa a abordagens de outras marcas, e que pode variar de baixa a alta.

- Ele se integra socialmente em uma "comunidade" que envolve e direciona as escolhas de forma satisfatória.

- Ele exerce sua auto-identidade correspondente apenas à marca escolhida e à 
"comunidade" identificada com esta marca.

Nesta linha de raciocínio, Oliver reviu sua modelagem de fidelização, passando a um novo paradigma, coposto por quatro tipos diferentes de estratégias conforme a chamada "força individual" e o "apoio social" sejam combinados em alto e baixo (ver Quadro 1). A fidelidade definitiva ocorreria quando ambos os elementos fossem alto, ponto no qual seria gerada uma auto-identidade imersa no sistema social do qual a marca faz parte, com o cliente ali se aprofundando, numa situação sinérgica.

\section{Quadro 1 - Quatro Estratégias da Fidelidade}

\begin{tabular}{|c|c|c|c|}
\hline & & \multicolumn{2}{|c|}{ Apoio social/da comunidade } \\
\hline \multirow{3}{*}{$\begin{array}{c}\text { "Força } \\
\text { ndividual" }\end{array}$} & & Baixo (estímulo passivo) & Alto (promoção proativa) \\
\hline & $\begin{array}{l}\text { Baixa (apenas } \\
\text { informaçōes da marca) }\end{array}$ & Superioridade do produto & Envolvimento da comunidade ${ }^{1}$ \\
\hline & $\begin{array}{l}\text { Alta (forte resistência à } \\
\text { troca: "fé cega") }\end{array}$ & Auto-isolamento espontâneo & $\begin{array}{l}\text { Auto-identidade imersa no sistema } \\
\text { social }\end{array}$ \\
\hline & $\begin{array}{l}10 \text { cliente aceita pa } \\
\text { usuários corporativos } \\
\text { Fonte: Oliver (1999 }\end{array}$ & jamente o ambiente da m & $\therefore$ plataformas de informática do \\
\hline
\end{tabular}

Como um dos exemplos deste tipo de comportamento, Oliver cita a "comunidade" criada pelos motociclistas adeptos da Harley Davidson (Harley Owners Group, H.O.G.). Como se fosse uma empresa, em seu site a H.O.G. informa que possui uma "missão" (Pilotar e divertir-se), e que seu objetivo primário é que a Harley Davidson, desde o executivo mais importante da empresa até seu mais novo motociclista, seja uma família grande e feliz, participando, por exemplo, de atividades beneficentes tais como o recolhimento de lixo nas estradas.

\section{ABORDAGEM À CRIAÇÃO DE VALOR DE PRAHALAD E RAMASWAMY (2004)}

Para Prahalad \& Ramaswamy (2004) vem sendo observado um paradoxo no mundo corporativo no século atual: cada vez mais escolhas são disponibilizadas aos consumidores sem que os ofertantes lhes consigam assegurar a obtenção de satisfação.

Sua análise parte do resgate dos conceitos aplicados na pesquisa sobre estratégias empresariais ao final do século XX e início do século XXI, baseados na premissa de que as empresas "antigas" e consolidadas (chamadas de "tipo A") não desapareceriam no futuro, assim como as novas e exuberantes empresas "ponto com" (as "tipo B") não necessariamente sobreviveriam. 0 que aconteceria seria o aparecimento de um novo tipo de empresas (as "tipo C") a partir da fusão e evolução das empresas A e B.

Examinando mais a fundo este fenômeno previsto, os autores verificaram que o cliente poderia participar ativamente no processo pelo qual todas estas empresas geram valor - ou seja, o cliente e a empresa estariam intimamente envolvidos na criação conjunta de valor que é diferenciado para o cliente e sustentável para a firma.

Nesta nova visão conceitual, estaria sendo questionado o universo convencional das empresas dos tipos A e B, no qual quase todo o trabalho estava centrado nelas - daí a categorização tradicional dos negócios em business-to-business (B2B) e business-to-consumer (B2C), ambos colocando o negócio (business) em primeiro ligar, numa visão da economia centrada na empresa, onde esta cria e oferece valor aos clientes.

Nesta linha de raciocínio, os autores propuseram um modelo de atividade econômica 
consumer-to-business-to-consumer (C2B2C). Ele desafia as noções tradicionais de valor e de sua criação, assim como os dois princípios fundamentais de nosso sistema industrial, conforme sugere que: 1 ) os esforços conjuntos do cliente e da empresa - por meio da rede de relacionamentos das empresas e das comunidades dos clientes - sejam capazes de co-criarem valor por meio de experiências personalizadas que são específicas para cada cliente em especial; 2) estariam em cheque os princípios do valor em si, do processo de criação de valor, e da natureza do relacionamento entre a empresa e o cliente.

Neste novo paradigma, a empresa e o cliente criariam valor conjuntamente nos chamados "pontos de interação", momentos e locais onde a experiência de co-criação ocorre, com os clientes exercendo suas escolhas e o valor sendo criando em conjunto. Ou seja, é eliminado o conceito tradicional de que as empresas pensam e agem unilateralmente. No caso, o papel do cliente passa a ser fundamental nesta criação de valor, conforme deixa de ser um ente isolado e passivo para tornar-se conectado e ativo, características que trazem impactos diversos.

Com acesso à informação - por exemplo, via Internet - os clientes passam a ter uma visão globalizada dos bens e serviços, e não mais aquela informação tradicional restrita a limites geográficos. Com isto, os clientes expandem seus padrões de preferência de consumo para além das fronteiras tradicionais, passando a desafiar as tradições das indústrias mais variadas acostumadas a restringirem suas informações. Por exemplo, de simples pacientes, aqueles que necessitam de ajuda médica passam a agir como clientes ativos dos cuidados médicos, procurando, na Internet, informações sobre os tratamentos, pesquisando sobre a qualidade dos hospitais e compartilhando suas experiências com outras pessoas.

0 recurso da Internet, aliado aos fortes avanços na comunicação de voz e de dados - via telefonia celular, por exemplo - ao garantir o crescimento da comunicação entre os clientes também tem dado margem ao aparecimento das comunidades temáticas de clientes. Ali eles compartilham idéias sem a interferência de barreiras sociais ou geográficas, e - o que é mais importante - de forma independente das empresas que desejam serví-los. Com isto, o padrão tradicional das comunicações de marketing "de cima para baixo" (ou seja, da empresa para o público) passa a inverter-se, conforme a rede de comunicação dos clientes consegue ser muito eficiente na divulgação dos custos e benefícios associados ao consumo de um bem ou serviço.

Por isto mesmo, a Internet fez surgir aquilo que Prahalad \& Ramaswamy chamam de ativismo dos clientes, que passam a dispor de poderosa arma para consolidarem suas posições no que se refere aos mais variados tipos de consumo. Como exemplo, têm-se os blogs, que, por meio da visão de um indivíduo sobre determinado assunto, expressado via textos, imagens e links na web, estimulam o debate público e a manifestação de opiniões. Outro exemplo são os sites criados especificamente para registrar as más experiências dos clientes ${ }^{1}$.

Por meio destas colocações, Prahalad \& Ramaswamy demonstram que tem havido uma forte mudança no papel dos clientes, e, por conseqüência, as empresas e provedores de serviços

“...não mais podem agir de forma autônoma, desenhando produtos, desenvolvendo processos de produção, construindo mensagens de marketing

1 Ver, por exemplo, www.reclameaqui.com.br. 
e controlando canais de vendas com pouca ou nenhuma interferência dos clientes." (p. 4-5)²

\section{INTEGRAÇÃO DO PARADIGMA DE ESTRATÉGIA EMPRESARIAL DE PRAHALAD E RAMASWAMY (2004) AO MODELO DE FIDELIZAÇÃO PROPOSTO POR OLIVER (1999)}

Como visto, o novo paradigma de criação de valor e de estratégia empresarial proposto por Prahalad \& Ramaswamy (2004) baseia-se em um conceito fundamental: a criação de valor deixa de ser um processo unilateral para tornar-se bilateral, já que o cliente passa a nele desempenhar papel determinante. Por outro lado, os autores também colocam que esta nova visão levanta questões importantes para os provedores de bens e de serviços, assim como propõem formas de estes últimos lidarem com esta nova realidade.

Segundo eles, há quatro "elementos construtores da co-criação de valor": diálogo, acesso, e transparência e avaliação do risco ${ }^{3}$ (DATA). Trata-se da mudança de paradigma em relação a quatro atitudes tradicionalmente interpretadas de maneira unilateral pelas empresas ou prestadores de serviço, embasados no princípio de que os clientes não deveriam compartilhar de seus posicionamentos na busca pela adição de valor àquilo que lhes é oferecido.

Abaixo, as especificidades dos quatro elementos construtores da co-criação de valor:

- Diálogo: definido como interatividade, engajamento profundo, propensão bilateral à ação; é a compreensão empática trazida pela experiência daquilo que os clientes experimentam, é o aprendizado compartilhado e a comunicação entre dois solucionadores de problemas com status iguais. Como contra-exemplos temos a incapacidade da indústria fonográfica em alinhar-se à crescente onda pela liberação do compartilhamento dos arquivos de música na Internet, assim como a teimosia de diversas empresas brasileiras em não buscarem a melhoria em seus atendimentos pósvenda que tanto aplaque a ira dos consumidores frustrados como melhore sua imagem frente ao grande público ${ }^{4}$.

- Acesso: enquanto o foco tradicional das empresas era criar e transferir a propriedade de produtos aos clientes, a meta dos clientes é, cada vez mais, terem acesso a experiências, e não obrigatoriamente à propriedade de algo. Não possuir o bem não necessariamente impede experimentá-lo, ou seja, a noção de acesso deve ser separada da noção de propriedade (ex.: o leasing de automóveis implicando acesso a um estilo de vida sem o comprometimento financeiro da aquisição, e os cyber cafés possibilitando acesso à web àqueles que não dispõem de poder de compra para adquirirem um computador).

- Transparência: remete ao rápido desaparecimento da assimetria de informação entre clientes e fornecedores de bens e de serviços, que tradicionalmente beneficiou estes últimos. Com isto, as empresas devem entender que não mais poderão gerenciar preços, custos e margens de lucro à revelia do público, conforme este último adquire

\footnotetext{
2 Muito embora no Brasil muito ainda reste a ser feito para que a opinião dos clientes seja levada a sério (ver BORGES, R. O consumidor ainda está em segundo plano. Jornal Valor Econômico, São Paulo, 21/06/2007, caderno Investimentos, acessado via site http://www.valor.com.br).

${ }^{3}$ Risco no sentido de probabilidade de prejuízo ao cliente.

${ }^{4}$ Em 30/12/07, o site www.reclameaqui.com.br indicava que, das vinte empresas virtuais e não virtuais com maiores quantidades de reclamações ali postadas do início de 2007 até aquele momento do ano, 25\% não haviam sido respondidas.
} 
acesso a mais informações sobre produtos e tecnologias. Como exemplo, temos a capacidade que os clientes atualmente detêm tanto de acompanhar, via Internet, a evolução do processo de entrega de suas compras feitas on line - evidenciando a (in)competência do vendedor e comparando-a com as promessas feitas por este como de verificarem os melhores preços dos bens e serviços demandados via sites de busca na Internet, checando a veracidade das propagandas que teimam em alardear as melhores condições do mercado.

- Avaliação do risco: remetendo à probabilidade de prejuízo ao cliente, trata-se de aspecto baseado no questionamento ao princípio tradicional de que as empresas saberiam, melhor do que o cliente, avaliar e administrar os riscos - o que explica por que, em sua comunicação com este último, elas tradicionalmente se concentram apenas em mostrar os benefícios dos seus produtos e serviços. No novo paradigma, este tipo de avaliação deveria ser compartilhado com os clientes. Com exemplo temos a incapacidade demonstrada pela fabricante norte-americana de sementes Monsanto em antecipar os riscos que cientistas e até pessoas leigas veriam nos alimentos geneticamente modificados, apesar da superioridade destes frente aos não geneticamente modificados em termos de rendimento econômico e de sua conseqüente colaboração para a eliminação da fome no mundo.

Combinando estes quatro elementos, as empresas poderiam criar capacitações novas e importantes:

- Acesso + Transparência: habilitam o cliente a escolher com maior segurança, já que ele se tornará mais bem informado. Um bom contra-exemplo foi a política dos bancos brasileiros de, até o final de 2007, usufruírem da liberdade concedida pelo Banco Central para construírem suas políticas de tarifas da forma menos transparente possível para com seus respectivos clientes. Com isto, deliberadamente optavam por mantê-los confusos, de forma a poderem usufruir de maiores rendas com a cobrança pelos seus serviços. A decisão tomada pelo Banco Central, em fins daquele ano, de, até certo ponto, normatizar este mercado, poderá implicar o aumento na concorrência entre as instituições bancárias. Pode-se imaginar que, num esforço para não perderem seus clientes, estas buscariam oferecer-lhes benefícios. Isto, em última instância, favoreceria as próprias instituições que melhor se saíssem nesta empreitada, conforme sua reputação melhorada alcançaria o domínio público e se traduziria em aumento na captação e retenção de clientes ${ }^{5}$.

- Diálogo + Avaliação do risco: esta associação, de acordo com Prahalad \& Ramaswamy, faculta o debate e o co-desenvolvimento de escolhas em políticas tanto públicas quanto privadas. 0 caso do movimento anti-tabagista é clássico, com os consumidores desempenhando papel relevante no desenhos das políticas públicas conforme as ações dos cidadãos vão moldando as novas tendências politicamente corretas.

- Acesso + Diálogo: trata-se da associação básica para o desenvolvimento e manutenção das chamadas "comunidades temáticas". No caso da mencionada comunidade H.O.G. dos motociclistas da Harley Davidson, a Internet é usada para seus membros se

\footnotetext{
${ }^{5}$ Não por acaso, já em setembro daquele ano o Itaú propagandeava redução em suas tarifas, atitude pioneira no setor bancário brasileiro - muito embora blogs de internautas questionassem a real contribuição que este movimento traria à economia dos clientes (ver, por exemplo, http://www.ericcoutinho.blog.br/lei-e-ordem/itau-reduz-tarifas/)
} 
inteirarem das atividades programadas e de muitas outras informações concernentes a este universo, ações que reforçam os laços entre os participantes.

- Transparência + Avaliação do risco: esta combinação serve ao codesenvolvimento da confiança. Um caso clássico se deu em fins do ano de 2007 nos EUA, quando, sob pressão de um relatório do Food and Drug Administration (FDA) ${ }^{6}$ que associava o excesso desses remédios a mortes em crianças, o Consumer Healthcare Products Association ${ }^{7}$ informou ter suspendido a venda do medicamento Tylenol na versão infantil no mercado norte-americano. Embora se tenha tratado de suspensão voluntária, em verdade respondeu a pressões crescentes por parte de entidades médicas e de agências do governo americano.

Com a nova dinâmica desta co-criação de valor, Prahalad \& Ramaswamy concluem que a adoção deste processo só é possível pelas empresas que desafiem os papéis tradicionais da empresa e do cliente no chamado de "ponto de interação" entre ambos.

Visto isto, fica fácil entender a ligação desta abordagem ao modelo de fidelização proposto por Oliver (1999). Conforme este último coloca que a comunidade da fidelidade é uma aliança social que garante características no comportamento do cliente que implicam uma fidelização ilimitada, este raciocínio pode ser associado aos elementos construtores de cocriação de valor mencionados por Prahalad \& Ramaswamy, em especial ao diálogo e ao acesso. Isto porque estes dois elementos seriam capazes de reforçar a mencionada auto-identidade imersa no sistema social do qual a marca faz parte, com o cliente ali se aprofundando, numa situação sinérgica gerada pelo alto apoio social/da comunidade, e que se conjuga a uma elevada força individual.

\section{CONCLUSÃO E SUGESTÃo}

A análise conjunta da proposta de Prahalad \& Ramaswamy ao modelo de fidelização de Oliver indica que a consolidação da fidelização definitiva se daria conforme a comunidade composta pelos demais consumidores da marca fosse reforçada pela atmosfera de comunidade leal entre cliente e produtor. Com isto se aliaria, ao conceito da comunidade à qual o cliente sentese com prazer de pertencer e que é formada pelos demais clientes, o da comunhão entre cliente e produtor trazida pela interatividade entre eles.

Com estas duas características asseguradas, os ofertantes de produtos físicos e de serviços teriam a garantia de alinhamento, a uma satisfação "intrínseca" dos clientes (ou seja, aquela de pertencerem a uma comunidade), um sentimento que poderíamos definir, de forma livre, como "de reconhecimento". Este sentimento significaria o reconhecimento, por parte da empresa ou do prestador de serviço, de que a colaboração daquele cliente se traduz em valor agregado cujo propósito específico é o de causar satisfação ao próprio cliente.

No caso daquilo que é necessário ao ofertante para atingir este objetivo, Prahalad \& Ramaswamy são específicos. A alta cúpula das empresas deve:

- Investir em desenvolver a capacidade de competir pelas experiência

- Desenvolver e articular um ponto de vista claro sobre o futuro

${ }^{6}$ Órgão regulador do mercado de medicamentos nos EUA.

${ }^{7}$ Entidade que representa os fabricantes de medicamentos nos EUA. 
- Reforçar o foco e as capacitações dos gestores

- Estimular a colaboração interna

- Apoiar e alimentar o ambiente do conhecimento (p. 205)

Já no que diz respeito à administração do relacionamento com o cliente, estes autores informam que a ênfase nos pontos tradicionalmente pregados pela metodologia customer relationship management (CRM) - redução de custos, modernização dos processos, eliminação do atrasos e melhoria da eficiência - deve mudar. Um novo CRM deveria ser praticado, baseado em perguntas tais como:

- Como podemos desenhar sistemas sob a perspectiva da experiência do cliente?

- Como manter os clientes interessados e evolvidos na co-criação?

- Como nossos sistemas podem acomodar uma grande quantidade de clientes heterogêneos? (p. 217)

Em sua parte final do livro, Prahalad \& Ramaswamy indicam algumas formas para que esta mudança ocorra. Por exemplo, a fabricante de automóveis Honda já estaria inserida neste novo modelo, conforme tem investido na manufatura global flexível. Trata-se de claro esforço para reconfigurar e recontextualizar o processo de fabricação, o supply chain e os sistemas de logística, a partir de pontos de interação já ativos com o cliente.

Mesmo assim, tratando-se de uma mudança de paradigma que embute uma série de ações aparentemente complexas para muitas empresas e prestadores de serviços, é natural que sua execução ainda esteja longe de ser uma regra no mundo empresarial.

Möller et al. (2007), por exemplo, examinando especificamente o segmento de serviços e aplicando, ao modelo Resource Based View, a descrição das condições e tipos de valores da cocriação e as atividades e competências na realização de valor, concluíram que: 1) os administradores ainda precisam entender melhor as estratégias da co-criação que impulsionam e sustentam a inovação dos serviços; 2) os pesquisadores precisam continuar a desenvolver conceitos, teorias e modelagens que capturem os desafios e oportunidades apresentados pelos modos de co-criação de serviços.

Também têm sido objeto de estudos as estratégias que os provedores de produtos e serviços podem utilizar para que seus clientes desempenhem adequadamente seus papéis, gerando a desejada co-produção que melhore a eficiência operacional, desenvolvendo as soluções ótimas e gerando vantagem competitiva sustentável.

Um exemplo de endereçamento desta questão pode ser encontrado em Bettencourt et al. (2002), que estudaram empresas de serviços conhecimento-intensivas, tais como as de consultoria de TI, nas quais os clientes rotineiramente desempenham papel importante na coprodução da solução do serviço em parceria com o produtor em si.

De qualquer forma, a ênfase tradicional na literatura de Marketing tem sido voltada às ações destinadas a lidar com este novo modelo de ação em nível exclusivamente empresarial. Seu foco geralmente se volta às implicações econômicas, demonstrando maior preocupação do que com as respostas psicológicas potenciais dos clientes à participação na co-criação de valor. Além de ser importante o incremento nos estudos voltados para o papel desempenhado 
pelos clientes neste processo, seria importante que a pesquisa acadêmica se aprofundasse no que se refere à melhor compreensão do engajamento dos clientes na co-criação de valor enquanto ferramenta de fidelização.

Alguns estudos acadêmicos têm construído orientações interessantes para esta investigação. Bendapudi \& Berry (1997), por exemplo, sugeriram que a receptividade dos clientes a este relacionamento com os ofertantes de bens e de serviços é afetada por quatro grandes drivers: variáveis comportamentais, de parceria, de cliente e de interação. Nesta linha de raciocínio, os autores propuseram que os clientes mantêm o relacionamento ou porque não têm alternativa ("têm" que permanecer no relacionamento) ou porque assim o desejam por uma questão de dedicação.

Já Bendapudi \& Leone (2003), examinando o aumento da participação dos clientes na produção de bens e de serviços, apoiaram seu trabalho na literatura psicológica do chamado self-serving bias. 0 termo remete ao desvio comportamental apresentado por uma pessoa quando ela tende a atribuir a si mesma o sucesso de algo (self-enhancing bias), e o respectivo insucesso a terceiros (self-protective bias). Trata-se de uma forma de proteção ao ego e de confirmação de atingimento de objetivos, também podendo ser observada quando existe a tendência à avaliação de uma informação ambígüa de forma benéfica aos interesses do avaliador.

Tendo realizado dois estudos destinados a examinar os efeitos da participação do cliente sobre sua própria satisfação sobre serviços ou produtos, no primeiro os autores apuraram que, consistentemente com o self serving bias, dado um resultado idêntico proveniente do consumo de um bem ou de um serviço, a satisfação do cliente para com a empresa difere caso ele tenha, ou não, participado respectivamente na produção ou prestação. 0 segundo estudo indicou que dar ao cliente a possibilidade de participar do resultado do produto ou serviço mitiga o self serving bias quando o resultado é aquém do esperado.

Portanto, fica a pergunta: até que ponto o processo de co-criação de valor pode efetivamente contribuir para a construção da fidelização dos clientes? Esta averiguação torna-se interessante conforme implica lidar-se com as especificidades do comportamento destes últimos, campo de estudo que envolve inúmeras idiossincrasias que há muito vêm sendo motivo de pesquisas nem sempre conclusivas. Afinal, clientes nem sempre são racionais, e diferem em suas percepções sobre atributos de experiência tais como confiança, conhecimento, desejo de dialogar e envolvimento, dentre outros.

\section{BIBLIOGRAFIA}

ANDERSON, E.W. \& SULLIVAN, M.W. The Antecedents and Consequences of Customer Satisfaction for Firms, Marketing Science, 12 (Spring), 125-43, 1993.

ARMSTRONG, W. E. A Note on the Theory of Consumer's Behaviour: Oxford Economic Papers, New Series, Vol. 2, No. 1, pp. 119-122, 1950.

ASSAEL, H. Consumer Behavior and Marketing Action: PWS-Kent Publishing Company, Boston, 4th ed, 1992.

BASS, F.M. The Theory of Stochastic Preference and Brand Switching. Journal of Marketing Research, Vol. 11, No. 1, pp. 1-20, 1974 
BENDAPUDI, N. \& BERRY, L. Customers' motivations for maintaining relationships with service providers. Journal of Retailing, Volume 73, Issue 1, Pages 15-37, 1997

BENDAPUDI, N. \& LEONE, R.P., "Psychological Implications of Customer Participation in CoProduction.”. Journal of Marketing, Jan. Vol. 67, 2003.

BETTENCOURT L., OSTROM A., BROWN, S., ROUNDTREE, R. Client Co-Production in Knowledge-Intensive Business Services. California Management Review, July, 2002

BETTMAN, J.R. An Information Processing Theory of Consurner Choice: Addison-Wesley Reading, Massachusetts, 1979

BROWN, T. M. Habit Persistence and Lags in Consumer Behaviour; Econometrica, Vol. 20, No. 3, pp. 355-371, 1952

COPELAND; M. Relation of Consumer's Buying Habits to Marketing Methods, Harvard Business Review, vol. 1, n. 2, p. 282-289, 1923

DESARBO, W.S., HUFF, L, ROLANDELLI, M. \& CHOI, J. On the measurement of perceived service quality: a conjoint analysis approach, IN Service Quality: New Directions in Theory and Practice, Roland T. Rust and Richard Oliver, eds. Thousand Oaks, CA: Sage Publications, 20122,1994

DICK, A. S., BASU, K. Customer loyalty: toward an integrated conceptual framework. Journal of the Academy of Marketing Science. vol. 22, p. 99-113, 1994.

EHRENBERG, A. Repeat Buying: Theory and Applications: North-Holland Publishing Co.,Amsterdam, 1972

JACOBY, J. A Model of Multi-Brand Loyalty. Journal of Advertising Research, vol. 11, n. 3, p. 25-31, 1971.

JACOBY, J. A Brand Loyalty Concept: Comments on a Comment. Journal of Marketing Research, vol. 12, n. 4, November, pp. 484-487, 1975

JACOBY, J. \& CHESTNUT, R. W. Brand Loyalty: Measurement and Management: Wiley, New York, 1978

JACOBY, J. \& KYNER, David B. Brand Loyalty vs. Repeat Purchasing Behavior. Journal of Marketing Research, Vol. 10, No. 1, February, pp. 1-9, 1973

JACOBY, J. \& OLSON, J. C. An Attitudinal Model of Brand Loyalty: Conceptual Underpinnings and Instrumentation Research. Conference on Attitude Research and Consumer Behavior, 1970

JONES, T. O. \& SASSER Jr., W. E. Why Satisfied Customers Defect. Harvard Business Review, November-December, 1995

MACHADO, F. B. Um estudo sobre os níveis de fidelidade do consumidor em serviços de naturezas distintas. Anais da XXVII Enanpad, Curitiba, 2004.

MASSY, W.F., MONTGOMERY, D.B. \& MORRISON, D.G. Stochastic Models of Buyimg Behaviour: MIT Press, Cambridge, Massachusetts, 1970 
MÖLLER, K., RAJALA, R. \& WESTERLUND, M.. Service Myopia? A New Recipe for ClientProvider Value Creation. The Berkeley-Tekes Service Innovation Conference in Berkeley, California, April 27-28, 2007.

MOWEN, J. Consumer Behavior: MacMillan Publishing Company, New York, 3rd ed., 1993.

O'LEARY. N. Brands on Trial. Adweek, vol. 34, n. 21, p. 24-31, 1993.

OLIVER, R. L. Satisfaction: A Behavioral Perspective on The Consumer: McGraw-Hill, 1997

OLIVER, R. L. Whence consumer loyalty? Journal of Marketing, Vol. 63 (Special Issue), 3344,1999 .

PRAHALAD, C.K. \& RAMASWAMY, V. The Future of Competition: Harvard Business School Press, Boston, Massachusetts, 2004

SAMUELSON, P. A Note on the Pure Theory of Consumer's Behaviour: An Addendum. Economica, New Series, Vol. 5, No. 19, August, pp. 353-354, 1938

SCHOUTEN, J.W. \& MCALEXANDER,J.H. Subcultures of Consumption: na Ethnography of the New Bikers, Journal of Consumption Research, 22 (June), 43-61, 1995

WILKIE, W.L. Consumer Behaviour: John Wiley \& Sons, New York, 2nd ed., 1990

\section{Sitiologia}

www.harley-davidson.com, acessado em 15 de dezembro de 2007. 